\title{
Peertechz
}

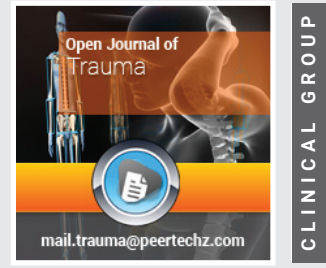

\section{Horner syndrome in traumatic brachial plexus injury}

\section{Antonija Krstačićc ${ }^{-3}$, Silva Butković Soldo ${ }^{2-4}$, Ana Bulić ${ }^{5}$, Goran Krstačić $2,3,6$}

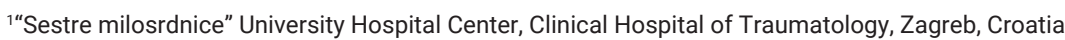
${ }^{2}$ Faculty of Dental Medicine and Health, Josip Juraj Strossmayer University of Osijek, Croatia

${ }^{3}$ The Faculty of Medicine, Josip Juraj Strossmayer University of Osijek, Croatia

${ }^{4}$ University Hospital Center Osijek, Clinic of Neurology, Croatia

${ }^{5}$ Student on Faculty of Dental Medicine and Health, Josip Juraj Strossmayer University of Osijek, Croatia ${ }^{6}$ Institute for Cardiovascular Disease and Rehabilitation, Zagreb, Croatia
Received: 01 June, 2020

Accepted: 20 July, 2020

Published: 21 July, 2020

*Corresponding author: Antonija Krstačić, MD, PhD, Assistant Professor, Clinical Hospital of Traumatology, "Sestre milosrdnice" University Hospital Center, Draškovićeva 19, HR-10000 Zagreb, The Faculty of Medicine, Josip Juraj Strossmayer University of Osijek Croatia, Tel: +385 098/881 548, +38514697 176; Fax: +38514610 365; E-mail: akrstacic@gmail.com Keywords: Brachial-plexopathy; Magnetic resonance imaging; Electrodiagnosis; Traumatic

https://www.peertechz.com

Check for updates
We report on a 29-year-old male patient, who presented at our clinic with mild left ptosis and miosis and with plegia of the left upper limb too. The patient also complained with severe crushing sensation and a constant burning over the left hand. He was injured in motorcycle collisions.

In neurological status, we found left Horner s syndrome and suspect left brachial plexus injury due to to associate plegia of the left upper limb with problems of persistent neuropathic pain in left upper extremity. His left arm had decreased tone and $0 / 5$ power from nerve roots $\mathrm{C}_{5}-\mathrm{T} 1$ with absent reflexes.

Electromyography (EMG) and nerve conduction studies were performed 2 weeks after the injury and showed the complete brachial plexus lesion, C5-C6-C7- Th1 - brachial plexus avulsion injury. Magnetic Resonance Imaging (MRI) of the brachial plexus demonstrated post-traumatic pseudomeningoceles at the level C6-C7 and C7-Th1. There are edematous changes in the trunks and divisions of the brachial plexus which are thickened and show increased signal intensity (Figure $1 \mathrm{~A}, \mathrm{~B}, \mathrm{C}$ ).

Surgical treatment was recommended, because the nerves fail to recovered. Autotransplantation $\mathrm{C}_{5}$ of axillary nerve and musculocutaneus nerve by medial cutaneus nerve of forearm was performed. Postoperatively, we demonstrate limited improvement in motor functional recovery in $\mathrm{C}_{5}$ myotome, obtained 10 months after implantation of peripheral nerve grafts. With medications we managed to control the neuropathic pain.
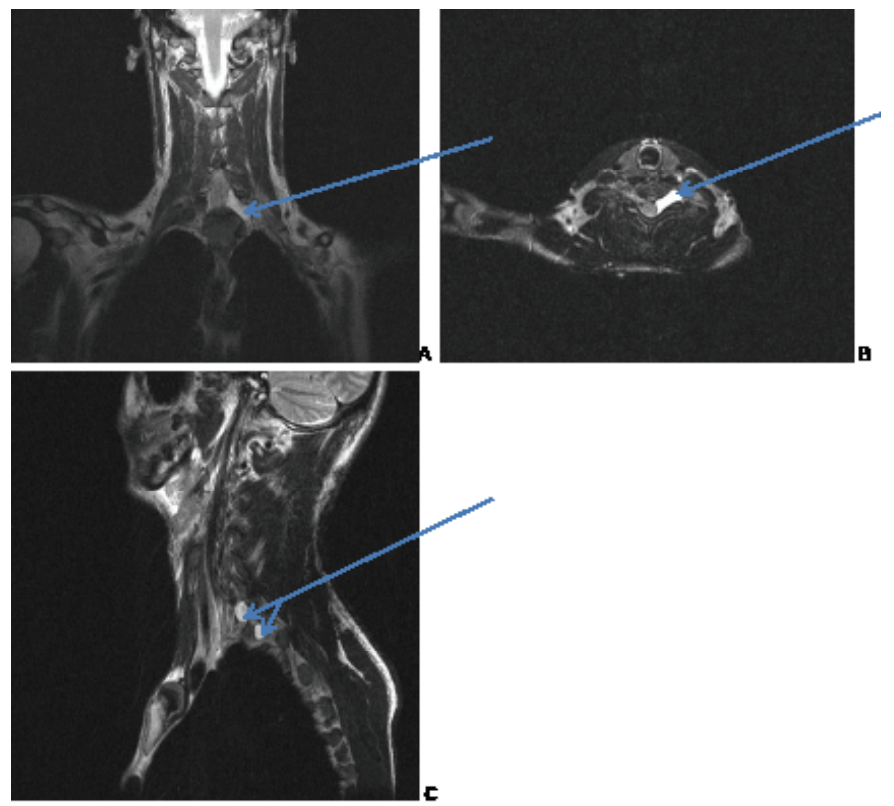

Figure 1: (A) coronal T2W sequences, axial (B) and sagital (C) demonstrate posttraumatic pseudomeningoceles in 2 different levels /at the level of C6-C7 and C7-T1 (arrowhead)/.

Horner's syndrome is an established clinical finding unique to traumatic brachial plexopathy, so we discuss the clinical utility of Horner's syndrome with regards to brachial plexopathy, as well as the utility of other diagnostic modalities in traumatic brachial plexopathy. The presence of Horner's syndrome further supported the presence of an brachial plexopathy, suggests C8-T1 root avulsion. 


\section{Discussion}

Horner syndrome results from an interruption of the sympathetic nerve supply to the eye and is characterized by the classic triad of miosis, partial ptosis, and loss of hemifacial sweating. The aetiology of Horner's syndrome is related to the location of the lesion [1]. First-order Horner's syndromes are disorders of the central nervous system, second-order neurons travel through the brachial plexus from the sympathetic trunk to the superior cervical ganglion. Third-order syndromes are commonly due to a lesion of the internal carotid artery. Complete brachial plexus avulsion injury is a severe disabling injury due to traction to the brachial plexus. Most traumatic brachial plexus injuries are axon degenerative and very often severe. The two commonest causes for brachial plexus injuries are motor cycle and road traffic accidents. Pseudomeningoceles are present in $80 \%$ of avulsions, i.e. approximately $20 \%$ of avulsions occur without forming pseudomeningoceles. Pseudomeningoceles may be large or small (saccular or diverticular), immediately against the foramen, they may extend over several levels, or they may lie anterior or posterior peri-spinally. Furthermore, Horner syndrome points to a preganglionic brachial plexus injury.

Different imaging modalities can be used to study the brachial plexus, including Magnetic Resonance Imaging (MRI), Computed Tomography (CT) and Ultrasound (US), Electrodiagnosis (EDX). MRI is the imaging modality of choice for the evaluation of the brachial plexus due to its superior soft tissue resolution and multiplanar capabilities [2,3].

Brachial plexus injuries represent devastating injuries with a poor prognosis. Nerve transfer or neurotization is mainly indicated in root avulsion injury [4].

Pain from the most severe types of brachial plexus injuries has been described as a debilitating. This pain resolves for most people within three years. The first signs of regeneration were noted approximately 9 to 12 months postoperatively.

\section{Conclusion}

Most traumatic brachial plexus injuries occur when the arm is forcefully pulled or stretched. Horner's syndrome is usually taken as an absolute indicator of avulsions of the C8 and T1 ventral roots in adult brachial plexus injury. Our case demonstrates a limited improvement in motor recovery of miotome $\mathrm{C}_{5}$ following surgery in patients with complete brachial plexus injury. Evaluation of the brachial plexus remains a challenge for the clinician and the radiologist.

\section{Informed consent}

Written informed consent was obtained from the patient for publication of this case report and any accompanying images.

\section{Conflict of interest}

The authors of this manuscript comply with the Principles of Ethical Publishing and have no conflict of interest.

\section{References}

1. Cağan $E$, Sayin $R$, Doğan $M$, Peker $E$, Cağan HH, et al. (2010) Bilateral brachial plexus palsy and right Horner syndrome due to congenital cervicothoracal syringomyelia. Brain Dev 32: 595-597. Link: https://bit.ly/2Ck643N

2. Torres C, Mailley K, del Carpio O'Donovan R (2013) MRI of the Brachial Plexus: Modified Imaging Technique Leading to a Better Characterization of Its Anatomy and Pathology. Neuroradiol J 26: 699-719. Link: https://bit.ly/2WCdbvo

3. Silbermann-Hoffmana O, Teboul F (2013) Post-traumatic brachial plexus MRI in practice. Diagnostic and Interventional Imaging 94: 925-943. Link: https://bit.ly/32wWntr

4. Bhandari PS, Sadhotra LP, Bhargava P, Bath AS, Mukherjee MK, et al. (2009) Surgical outcomes following nerve transfers in upper brachial plexus injuries. Indian J Plast Surg 42: 150-160. Link: https://bit.ly/2CjIGmZ

Discover a bigger Impact and Visibility of your article publication with

\section{Peertechz Publications}

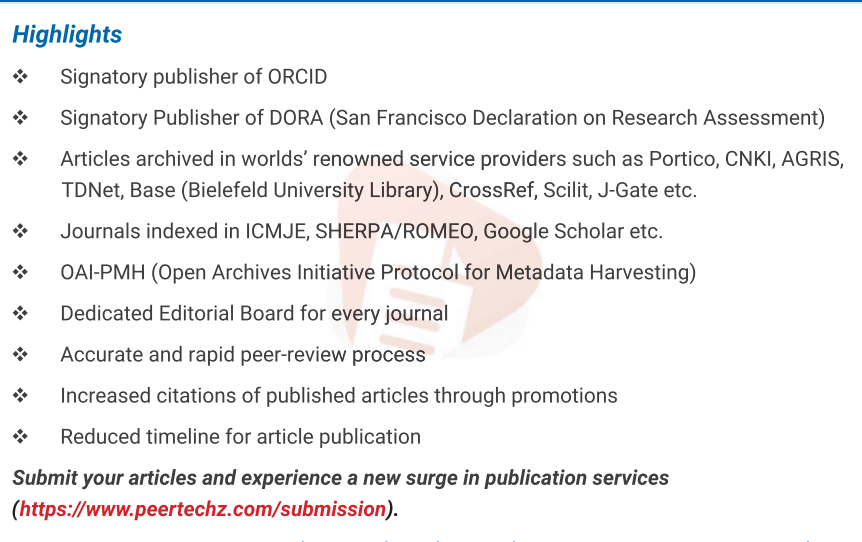

Peertechz journals wishes everlasting success in your every endeavours.

Copyright: @ 2020 Krstačić A, et al. This is an open-access article distributed under the terms of the Creative Commons Attribution License, which permits unrestricted use, distribution, and reproduction in any medium, provided the original author and source are credited. 